\title{
Strategi Penerjemahan dan Pergeseran Makna Istilah Budaya Sosial dalam Terjemahan Komik Garudayana Saga Volume 1- 4 Karya Is Yuniarto
}

\author{
Ni Wayan Dadi ${ }^{*}$, Ni Putu Luhur Wedayanti ${ }^{2}$, I Made Budiana ${ }^{3}$ \\ ${ }^{[123]}$ Program Studi Sastra Jepang Fakultas Ilmu Budaya \\ [ddadidudit@gmail.com] 2[1_wedayanti@yahoo.co.jp] \\ ${ }^{3}$ [budi.hybrid@gmail.com] \\ *Corresponding Author
}

\begin{abstract}
The title of this research is "Translation Strategies and The Shifting Meaning of Social Culture Terms in Translation of Garudayana Saga Volume 1-4 by Is Yuniarto". The research is aimed to analyze the translation strategies used by translator, and componential analysis of the social cultural terms in translation of the comic. The theories that were used in this research were theory of translation strategies proposed by Mona Baker (1992), theory of componential analysis proposed by Roger T. Bell (1993), and theory of cultural anthropological by Koentjaraningrat (2014). There are four categories of social cultural terms: work, leisure, greetings and idioms. There are seven strategies used by the translator: translation by general word, neutral word, cultural substitution, loan word or loan word plus explanation, paraphrase using related word, paraphrase using unrelated word and omitted word. Strategies that most used by translator were translation by general word and cultural substitution. These strategies were used due to differences in social cultural background of society in Indonesia and Japan. The least used strategies were paraphrase using unrelated word and omitted word, since the used of these two strategies can reduce the cause of the shifting meaning in translation.
\end{abstract}

Keywords: translation strategy, shifting meaning, social culture

\begin{abstract}
Abstrak
Penelitian ini berjudul "Strategi Penerjemahan dan Pergeseran Makna Istilah Budaya Sosial dalam Terjemahan Komik Garudayana Saga Volume 1-4 Karya Is Yuniarto". Tujuan penelitian ini adalah untuk mengetahui strategi penerjemahan istilah budaya sosial dan pergeseran makna istilah budaya sosial yang diakibatkan dari penggunaan strategi penerjemahan oleh penerjemah dalam terjemahan komik Garudayana Saga volume 1-4 karya Is Yuniarto. Teori yang digunakan adalah teori strategi penerjemahan oleh Mona Baker (1992), teori analisis komponen makna oleh Roger T. Bell (1993), dan teori pendekatan antropologi budaya oleh Koentjaraningrat (2014). Berdasarkan hasil penelitian, terdapat empat kategori istilah budaya sosial yaitu: pekerjaan, hiburan, sapaan dan idiom. Terdapat tujuh strategi penerjemahan yang digunakan penerjemah, yaitu: strategi penerjemahan dengan kata yang lebih umum, penerjemahan dengan kata yang lebih netral, penerjemahan dengan subtitusi budaya, penerjemahan dengan kata pinjaman, penerjemahan dengan parafrasa kata yang berkaitan, penerjemahan dengan parafrasa kata yang tidak berkaitan, dan penerjemahan dengan pelesapan. Strategi yang umum digunakan penerjemah dalam menerjemahkan istilah budaya sosial adalah strategi penerjemahan dengan kata yang lebih umum dan penerjemahan dengan subtitusi budaya. Hal ini diakibatkan karena adanya perbedaan latar budaya sosial masyarakat di Indonesia dan Jepang. Strategi yang sedikit digunakan adalah strategi penerjemahan dengan menggunakan parafrasa kata yang tidak berkaitan dan penerjemahan dengan pelesapan kata, karena penggunaan kedua strategi tersebut dapat mengurangi penyebab terjadinya pergeseran makna dalam penerjemahan.
\end{abstract}

Kata kunci: strategi penerjemahan, pergeseran makna, budaya sosial 


\section{Latar Belakang}

Penerjemahan tidak lagi dipandang hanya sebagai proses pengalihan makna kata dari satu bahasa ke bahasa lainnya. Akan tetapi, penerjemahan telah berkembang menjadi sarana penyebaran informasi, ide dan nilai-nilai kultural untuk mengembangkan ilmu pengetahuan dan budaya serta meningkatkan pemahaman dan kerjasama interkultural di dalam masyarakat modern. Penerjemahan memiliki kaitan yang sangat erat dengan kebudayaan yang melatarbelakangi bahasa sumber dan bahasa sasaran. Hal tersebut di-sebabkan karena bahasa merupakan penggambaran kebudayaan penutur.

Menurut Bugarski (1985:159), unsur-unsur dan sistem-sistem kebudayaan mulai dari unsur makanan, pakaian, pekerjaan, hiburan, olahraga, sampai dengan sistem ekonomi, politik, agama, hukum dan filsafat, seringkali tidak cocok diantara dua kebudayaan yang digambarkan oleh bahasa masingmasing, baik itu bahasa penutur maupun bahasa sasaran. Perbedaan unsur dan sistem tersebut tentu saja menimbulkan masalah dalam bidang terjemahan karena terjemahan tidak hanya pengoperasian interlinguistik saja tetapi juga antar budaya.

Penelitian mengenai istilah budaya sosial yang mengambil objek bahasa sumber yakni bahasa Indonesia dan bahasa sasaran yakni bahasa Jepang belum banyak dilakukan sehingga sangat menarik untuk diteliti. Berdasarkan alasan tersebut beserta pemaparan yang telah disampaikan sebelumnya, penulis menganalisis strategi penerjemahan dan pergeseran makna istilah budaya sosial dalam komik Garudayana Saga volume 1-4 karya Is Yuniarto dan terjemahan komik Garuudayana Saaga yang diterjemahkan oleh Hirayanagi Ryuuki.

\section{Pokok Permasalahan}

Rumusan masalah dalam penelitian ini adalah sebagai berikut.

a. Bagaimanakah strategi penerjemahan istilah budaya sosial yang terdapat dalam terjemahan komik Garudayana Saga volume 1-4 karya Is Yuniarto?

b. Bagaimanakah pergeseran makna istilah budaya sosial yang terdapat dalam terjemahan komik Garudayana Saga volume 1-4 karya Is Yuniarto?

\section{Tujuan penelitian}

Adapun tujuan dari penelitian ini, sebagai berikut. 1) Untuk mengetahui strategi penerjemahan istilah budaya sosial yang terdapat dalam terjemahan komik Garudayana Saga volume 1-4 karya Is Yuniarto. 2) Untuk mengetahui pergeseran makna istilah budaya sosial dalam terjemahan komik Garudayana Saga volume 1-4 karya Is Yuniarto.

\section{Metode Penelitian}

Penelitian ini dianalisis menggunakan metode deskriptif kualitatif (Djajasudarma, 2010:16). Teori yang digunakan adalah teori strategi penerjemahan oleh Baker (1992) untuk menganalisis strategi penerjemahan dan teori analisis komponen makna oleh Bell (1993) digunakan untuk meng-analisis pergeseran makna yang ditimbulkan akibat penggunaan strategi penerjemahan istilah budaya sosial dalam komik. Teori pendekatan antropologi budaya oleh Koentjaraningrat (2014) digunakan sebagai teori penunjang dalam analisis.

\section{Hasil dan Pembahasan}

Terdapat 39 data istilah budaya sosial dalam teks sumber dan 38 data istilah budaya sosial dalam teks sasaran. Jumlah data yang berbeda disebabkan karena adanya satu data dalam teks sa- 
saran yang memiliki dua variasi terjemahan dan dua data dalam teks sasaran yang tidak diterjemahkan.

\subsection{Strategi Penerjemahan dengan Menggunakan Kata yang Lebih Umum}

Strategi penerjemahan dengan menggunakan kata yang lebih umum digunakan untuk mencari padanan kata dari berbagai macam kata yang tidak memiliki padanan langsung. Berikut salah satu data dalam analisis yang menggunakan strategi penerjemahan dengan menggunakan kata yang lebih umum.

\section{(1) $\mathrm{TSu} \quad$ : Gadis sial \\ $\mathrm{TSa}$ : 生意気娘}

\section{(Namaiki Musume)}

Istilah gadis sial merupakan istilah yang digunakan untuk menyebutkan seorang anak perempuan yang membawa nasib buruk atau mendatangkan kemalangan. Namun, dalam komik terjemahannya diterjemahkan menjadi istilah 'namaiki musume' dengan kata yang lebih umum dan berarti "gadis yang lancang". Jika dibandingkan dengan terjemahannya, istilah 'namaiki musume' sama sekali tidak menunjukkan seseorang yang membawa kemalangan atau hal-hal buruk. Terjadi pergeseran makna dalam proses penerjemahan istilah gadis sial. Hal tersebut dapat diketahui dari analisis komponen makna pada tabel 1 .

Tabel 1. Analisis Komponen Makna Gadis Sial dan 'Namaiki Musume'

\begin{tabular}{clcc}
\hline No & \multicolumn{1}{c}{$\begin{array}{c}\text { Komponen } \\
\text { Makna }\end{array}$} & $\begin{array}{c}\text { Gadis } \\
\text { Sial }\end{array}$ & $\begin{array}{c}\text { 生意 } \\
\text { 気娘 }\end{array}$ \\
\hline$(1)$ & Anak perempuan & + & + \\
\hline$(2)$ & Belum menikah & + & + \\
\hline$(3)$ & $\begin{array}{l}\text { Mendatangkan } \\
\text { kemalangan }\end{array}$ & + & - \\
\hline$(4)$ & $\begin{array}{l}\text { Membawa } \\
\text { pengaruh buruk }\end{array}$ & + & - \\
\hline \multicolumn{4}{l}{ Komponen yang menjadi pembeda } \\
dalam istilah gadis sial dan 'namaiki mu-
\end{tabular}

sume' yaitu "mendatangkan kemalangan" dan "membawa pengaruh buruk". Gadis sial merupakan anak perempuan yang mendatangkan kemalangan, membuat rencana seseorang gagal karena kehadirannya sehingga membawa pengaruh buruk bagi orang lain. Berbeda dengan 'namaiki musume' yang dapat diartikan sebagai "gadis yang angkuh" atau "gadis yang lancang". Oleh karena itu, penerjemahan istilah gadis sial menjadi 'namaiki musume' mengalami pergeseran makna.

\subsection{Strategi Penerjemahan dengan Kata yang Lebih Netral}

Strategi ini digunakan untuk mengurangi kesan negatif yang ditimbulkan oleh kata dalam bahasa sumber akibat makna dalam bahasa sumber tersebut. Berikut pemaparan salah satu data dengan menggunakan strategi ini.

$$
\begin{aligned}
\text { (2) TSa } & \text { : Judi } \\
\mathrm{TSu} & \text { : 賭け (Kake) }
\end{aligned}
$$

Judi merupakan pertaruhan sengaja yang mempertaruhkan sesuatu yang bernilai dengan menyadari resiko tertentu atau belum pasti hasilnya (Kartono, 1981:52). Istilah judi dalam bahasa sumber dianggap sebagai sesuatu yang negatif dan secara hukum dianggap sebagai tindak pidana. Sebaliknya, dalam bahasa sasaran, judi dianggap memiliki hukum yang aneh karena masing-masing wilayah di Jepang memiliki aturan yang berbeda-beda dalam perjudian (Japan Zone, 2017). Tidak terjadi pergeseran makna dalam menerjemahkan istilah judi menjadi 'kake'. Berikut analisis komponen makna pada tabel 2 .

Tabel 2. Analisis Komponen Makna Judi dan 'Kake'

\begin{tabular}{llcc}
\hline No & $\begin{array}{c}\text { Komponen } \\
\text { Makna }\end{array}$ & Judi & 賭け \\
\hline (1) & $\begin{array}{l}\text { Pertaruhan } \\
\text { dengan } \\
\text { uang/barang }\end{array}$ & + & + \\
\hline
\end{tabular}




\begin{tabular}{llll}
\hline (2) & $\begin{array}{l}\text { Dilakukan } \\
\text { dengan sengaja }\end{array}$ & + & + \\
\hline (3) & $\begin{array}{l}\text { Pemenang } \\
\text { mendapat } \\
\text { uang/barang }\end{array}$ & + & + \\
\hline
\end{tabular}

Hampir seluruh komponen makna yang dimiliki oleh istilah judi dimiliki juga oleh terjemahannya yaitu 'kake'. Oleh karena itu, penerjemahan istilah judi menjadi ' $k a k e$ ' tidak mengalami pergeseran makna.

\subsection{Strategi Penerjemahan dengan Subtitusi Budaya}

Strategi penerjemahan dengan menggunakan subtitusi budaya digunakan dengan mengganti konsep kebudayaan pada bahasa sumber dengan konsep kebudayaan pada bahasa sasaran yang memiliki makna serupa dengan bahasa sumber. Berikut salah satu data yang menggunakan strategi ini.

(3) TSu : Punakawan

TSa : 1) 仲間 (Nakama)

\section{2) 正義の味方 (Seigi no Mikata)}

Istilah punakawan berarti pelayan atau pengawal raja/bangsawan pada zaman dahulu (Alwi dkk, 2005:907). Punakawan juga mengacu pada tokoh multiperan yang dapat menjadi penasihat para penguasa bahkan dewa. Berperan juga sebagai penghibur, kritikus sekaligus menjadi penyampaian kebenaran dan kebajikan (Kresna, 2012:20). Sedangkan istilah 'nakama' mengacu pada seorang teman yang sering diajak bergaul dan melakukan sesuatu bersama-sama (Shirou dkk, 2006:858). Untuk memudahkan pembaca memahami istilah punakawan, penerjemah mencari padanan kata dalam bahasa Jepang yang merupakan istilah untuk menyebut 'kawan'. Terjadi pergeseran makna dalam menerjemahkan istilah punakawan. Hal tersebut dapat dilihat pada analisis komponen makna pada tabel 2 berikut ini.
Tabel 3. Analisis Komponen Makna Punakawan, 'Nakama', dan 'Seigi no Mikata'

\begin{tabular}{|c|c|c|}
\hline No & $\begin{array}{c}\text { Komponen } \\
\text { Makna }\end{array}$ & $\begin{array}{l}\text { Puna- } \\
\text { kawan }\end{array}$ 仲間 \\
\hline
\end{tabular}

味方

\begin{tabular}{lllll}
\hline (1) $\begin{array}{l}\text { Pengawal } \\
\text { raja/bang- } \\
\text { sawan }\end{array}$ & + & - & - \\
\hline (2) & $\begin{array}{l}\text { Teman } \\
\text { sepergaulan }\end{array}$ & + & + & + \\
\hline (3) & $\begin{array}{l}\text { Seorang } \\
\text { teman yang } \\
\text { mengerti }\end{array}$ & + & \pm & \pm \\
\hline (4) & $\begin{array}{l}\text { Penghibur } \\
\text { dan kritikus }\end{array}$ & + & - & - \\
\hline & Komponen pembeda kedua istilah
\end{tabular}
tersebut yaitu "pengawal raja/bangsawan" dan "penghibur dan kritikus" yang masing-masing ditandai dengan tanda minus (-). Istilah 'nakama' maupun 'seigi no mikata' tidak memiliki makna sesuai dengan istilah punakawan. Punakawan adalah modifikasi atas sistem penyebaran ajaran-ajaran agama Islam oleh Sunan Kalijaga dalam sejarah penyebarannya di Indonesia terutama di pulau Jawa (Kresna, 2012:20). Oleh karena itu, dalam proses penerjemahan istilah punakawan menjadi 'nakama' maupun 'seigi no mikata' mengalami pergeseran makna.

\subsection{Strategi Penerjemahan dengan Menggunakan Kata Pinjaman (Loan Words)}

Strategi ini digunakan ketika ditemukan konsep-konsep modern atau kata-kata penting. Berikut data yang menggunakan strategi ini.

(4) TSa : Kesatria Jangkarbumi 


\section{$\mathrm{TSu}$ : 大地をつなぐ戦士}

\section{(Daichi wo tsunagu senshi).}

Istilah Kesatria Jangkarbumi merujuk pada seorang prajurit yang gagah berani dan berasal dari Jangkarbumi. Jangkarbumi merupakan sebuah kerajaan dan istana para naga serta ular yang pemimpinnya adalah seseorang bernama Antareja. Namun, dalam bahasa sasaran diterjemahkan dengan istilah 'daichi wo tsunagu senshi' yang berarti "prajurit yang menyatukan dunia". Terjadi pergeseran makna istilah Kesatria Jangkarbumi menjadi 'daichi wo tsunagu senshi'. Berikut tabel pemaparannya.

Tabel 4. Analisis Komponen Makna Kesatria Jangkarbumi dan 'Daichi wo Tsunagu Senshi'

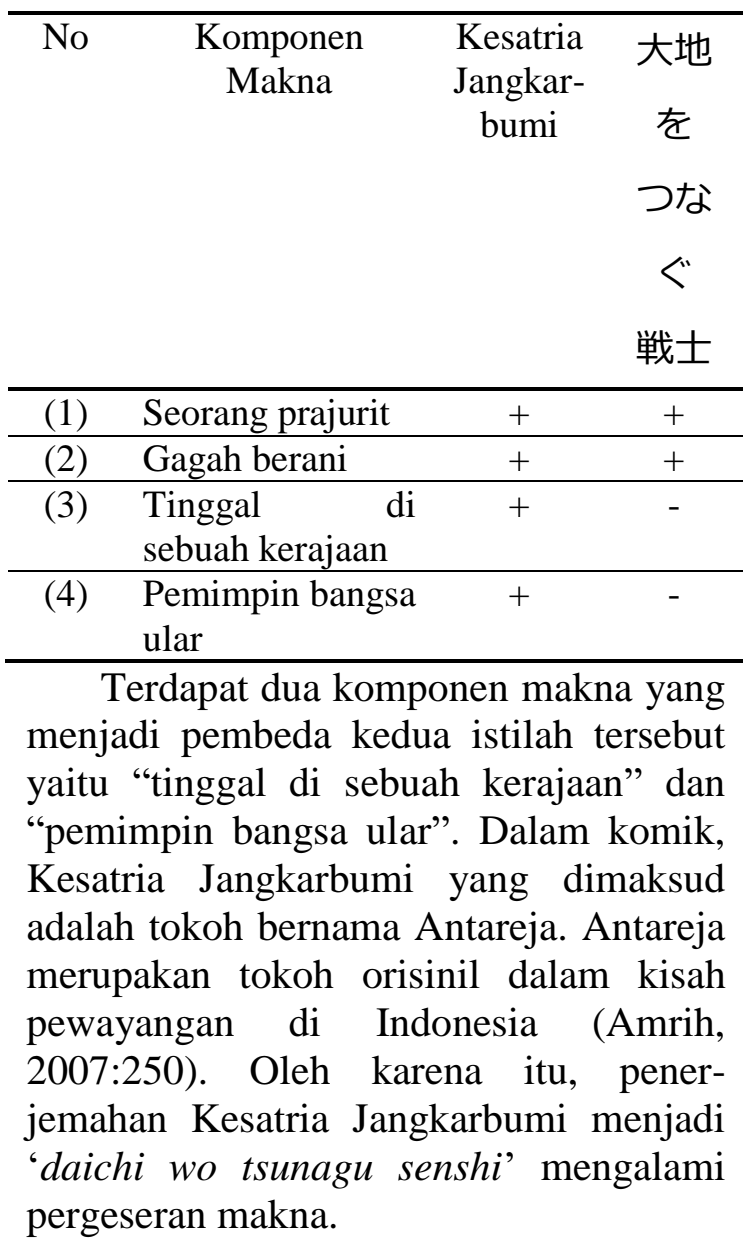

\subsection{Strategi Penerjemahan dengan Menggunakan Parafrasa Kata yang Berkaitan}

Strategi ini digunakan ketika istilah dalam bahasa sumber mempunyai padanan dalam bahasa sasaran, namun memiliki perbedaan bentuk. Berikut merupakan data yang menggunakan strategi ini.

$$
\begin{aligned}
\text { (5) TSa } & \text { : Tangan kosong } \\
\mathrm{TSu} & \text { : 手ぶら (Tebura) }
\end{aligned}
$$

Istilah 'tebura' dalam bahasa sasaran merujuk pada tangan yang tidak membawa apapun. Istilah tersebut mempermudah pembaca memahami istilah tangan kosong dengan menggunakan kata kunci 'tebura'. Tidak terjadi pergeseran makna dalam penerjemahan kedua istilah tersebut. Berikut merupakan analisis komponen makna istilah tangan kosong dan 'tebura'.

Tabel 5. Analisis Komponen Makna Tangan Kosong dan 'Tebura'

\begin{tabular}{clcc}
\hline No & $\begin{array}{c}\text { Komponen } \\
\text { Makna }\end{array}$ & $\begin{array}{c}\text { Tangan } \\
\text { Kosong }\end{array}$ & $\begin{array}{c}\text { 手ぶ } \\
\text { ら }\end{array}$ \\
\hline (1) & Tangan hampa & + & + \\
\hline$(2)$ & $\begin{array}{l}\text { Tidak membawa } \\
\text { hasil }\end{array}$ & + & + \\
\hline (3) & $\begin{array}{l}\text { Tidak } \\
\text { mengandung arti }\end{array}$ & + & \pm \\
\hline
\end{tabular}

Hampir seluruh komponen makna yang dimiliki oleh istilah tangan kosong dimiliki juga oleh terjemahannya yaitu 'tebura'. Komponen makna "tidak mengandung arti" pada istilah 'tebura' ditandai dengan tanda plus minus $( \pm)$ karena dalam budaya bahasa sasaran, 'tebura' bukan berarti sebuah sesuatu yang tidak memiliki arti, namun merupakan istilah yang digunakan ketika seseorang tidak membawa oleh-oleh ketika berkunjung ke rumah seseorang.

\subsection{Strategi Penerjemahan dengan Menggunakan Parafrasa Kata yang Tidak Berkaitan}


Strategi penerjemahan dengan menggunakan parafrasa kata yang tidak berkaitan digunakan untuk mengungkapkan makna istilah yang terdapat dalam bahasa sumber dengan menggunakan kata atau frasa yang berbeda. Berikut data yang menggunakan strategi ini.

(6) TSa : Panggung ria jenaka

$\mathrm{TSu}$ : どきどきショー (Dokidoki shoo)

Panggung ria jenaka dalam komik Garudayana Saga mengacu pada sebuah pertunjukkan yang riang dan gembira serta dapat membangkitkan tawa. Sedangkan, terjemahannya yakni 'doki-doki shoo' mengacu pada sebuah pertunjukkan yang berbahaya dan mendebarkan. Terjadi pergeseran makna pada kedua istilah tersebut. Hal tersebut dapat diketahui dari analisis komponen makna pada tabel 6.

Tabel 6. Analisis Komponen Makna Panggung Ria Jenaka dan 'Doki-doki Shoo'

\begin{tabular}{|c|c|c|c|}
\hline No & $\begin{array}{l}\text { Komponen } \\
\text { Makna }\end{array}$ & $\begin{array}{l}\text { Panggung } \\
\text { Ria } \\
\text { Jenaka }\end{array}$ & $\begin{array}{c}\text { どき } \\
\text { どき } \\
\text { ショ } \\
\text { - }\end{array}$ \\
\hline (1) & $\begin{array}{l}\text { Pertunj } \\
\text { sandiw }\end{array}$ & + & + \\
\hline (2) & $\begin{array}{l}\text { Penuh suka-cita } \\
\text { dan menghibur }\end{array}$ & + & + \\
\hline (3) & $\begin{array}{l}\text { Membangkit-kan } \\
\text { tawa }\end{array}$ & + & \\
\hline \multicolumn{4}{|c|}{$\begin{array}{l}\text { Komponen makna 'membangkitkan } \\
\text { tawa" ditandai dengan tanda minus (-) } \\
\text { yang berarti komponen tersebut tidak } \\
\text { dimiliki oleh istilah 'doki-doki shoo'. } \\
\text { Istilah 'doki-doki shoo' merupakan se- } \\
\text { suatu yang menyebabkan ketegangan dan } \\
\text { perasaan gugup, bukan membangkitkan } \\
\text { tawa. Penerjemah menggunakan istilah } \\
\text { 'doki-doki shoo' untuk menyesuaikan ke- }\end{array}$} \\
\hline
\end{tabular}

adaan dengan adegan dalam komik yang menceritakan bahwa anggota punakawan mengadakan pertunjukkan panggung ria jenaka. Namun, pertunjukkan yang dihadirkan justru berisi adegan berbahaya, sehingga penerjemah menyesuaikannya dengan adegan pada komik. Oleh karena itu, penerjemahan panggung ria jenaka menjadi 'doki-doki shoo' mengalami pergeseran makna.

\subsection{Strategi Penerjemahan dengan Menggunakan Pelesapan}

Strategi ini digunakan jika makna dari suatu kata tidak begitu penting, dan tidak mengurangi makna dari isi pesan yang ingin disampaikan. Berikut ini merupakan data yang menggunakan strategi dengan pelesapan kata.

(7) $\mathrm{TSu}$ : Huh, dasar gadis pemimpi tak tahu diri! Lihat keadaanmu sekarang!

(GS-I Volume 4, 2014:106)

$\mathrm{TSa}$ : ふつ、自分 の

Fuh, jibun no Huh, diri sendiri GEN 置かれている 状況

Okarete iru joukyou menempatkan situasi

$\begin{array}{ll}\text { が } & \text { わかってる } \\ \text { ga } & \text { wakatte iru } \\ \text { NOM } & \text { mengerti }\end{array}$

$\begin{array}{ll}\text { の? まわり } & \text { を } \\ \text { no? mawari } & \text { wo } \\ \text { SHU sekeliling } & \text { AK }\end{array}$

見渡して ごらん

miwatashite goran melihat coba 


\section{よ! \\ yo! \\ SHU}

(GS-J Volume 4, 2013:106)

Dalam teks sumber terdapat istilah gadis pemimpi, namun dalam terjemahan teks sasarannya, istilah tersebut dihilangkan. Istilah gadis pemimpi adalah anak perempuan yang suka mengkhayal dam bermimpi meskipun tidak dalam keadaan tidur. Pada teks sasaran istilah tersebut diterjemahkan menjadi kalimat 'jibun no okareteiru jyoukyou ga wakatteiru no?' yang memiliki arti "apakah kau sadar situasi yang sedang kau hadapi?". Pelesapan istilah gadis pemimpi tidak memengaruhi isi pesan yang disampaikan penerjemah.

\section{Simpulan}

Berdasarkan analisis yang telah dilakukan, dapat disimpulkan bahwa terdapat tujuh strategi penerjemahan yang digunakan oleh penerjemah untuk menerjemahkan istilah budaya sosial dalam komik Garudayana Saga volume 1-4 karya Is Yuniarto. Strategi yang paling umum digunakan oleh penerjemah adalah strategi penerjemahan dengan menggunakan kata yang lebih umum dan menerjemahkan dengan subtitusi budaya. Sedangkan, strategi yang paling sedikit digunakan oleh penerjemah adalah menerjemahkan dengan menggunakan parafrasa kata yang tidak berkaitan dan menerjemahkan dengan pelesapan kata.

Pergeseran makna yang terjadi diakibatkan oleh perbedaan budaya yang dimiliki bahasa sasaran dengan budaya dalam bahasa sumber. Budaya yang dimaksud adalah budaya sosial yang memiliki sejarah asal serta perkembangannya mengikuti budaya asli Indonesia, sehingga tidak terdapat dalam budaya bahasa sasaran yakni bahasa Jepang. Latar masyarakat serta kondisi sosial di
Indonesia berbeda dengan masyarakat di Jepang juga menjadi penyebab sulitnya menemukan padanan kata yang sesuai sehingga pergeseran makna dalam menerjemahkan sebuah istilah, menjadi tidak dapat dihindari. Selain itu, pergeseran makna tersebut terjadi karena penerjemah menerjemahkan istilah dalam bahasa sumber menjadi istilah yang dapat menarik minat pem-baca bahasa sasaran. Terjadinya pergeseran makna dalam menerjemahkan istilah budaya tidak terlalu menjadi masalah besar jika pergeseran makna yang terjadi tidak mengubah isi pesan. Namun, seorang penerjemah sebaiknya memiliki pengetahuan tentang budaya, serta mengetahui dasar filosofi dari terbentuknya sebuah istilah dalam masyarakat, sehingga hal tersebut dapat meminimalisir terjadinya kenirpadanan dalam menerjemahkan suatu istilah.

\section{Daftar Pustaka}

Alwi, Hasan dkk. 2005. Kamus Besar Bahasa Indonesia Edisi Ketiga. Jakarta: Balai Pustaka

Amrih, Pitoyo. 2007. Narasoma: Ksatria Pembela Kurawa. Yogyakarta: Pinus Book

Baker, Mona. 1992. In Other Words: A Coursebook on Translation. New York: Routledge

Bell, Roger T. 1993. Translation and Translating: Theory and Practice. New York: Longman

Bugarski, Ranko. 1985. Translation Across Cultures: Some Problems with Terminologies. John Benjamins Publishing Company

Djajasudarma, Fatimah. 2010. Metode Linguistik: Ancangan Metode Penelitian dan Kajian. Jakarta: Refika Aditama 
Yuniarto, Is. 2014. Garudayana Saga Volume 1 sampai 4. Jakarta: Koloni

Japan Zone. 2 Februari 2017. Gambling Law in Japan. https://www.japanzone.com/features/021_gambling _law_in_japan.shtml (Diunduh 7 Februari 2018)

Kartono, Kartini. 1981. Patologi Sosial Jilid I. Jakarta: Rajawali Press

Koentjaraningrat. 2014. Pengantar Antropologi I. Jakarta: PT Rineka Cipta

Kresna, Ardian. 2012. Punakawan Simbol Kerendahan Hati Orang Jawa. Yogyakarta: Narasi

Ryuuki, Hirayanagi. 2013. Garuudayana Saaga Volume 1 sampai 4. Tokyo: Digital Comic Catapult

Shirou, Hayashi dkk. 2006. Reikai: Shinkokugo Jiten. Tokyo:

Sanseido 